\title{
POLÍTICAS DE REGULARIZACIÓN DOMINIAL DE TIERRAS RURALES: EL PLAN DE LA PROVINCIA DE CORRIENTES, ARGENTINA ${ }^{1}$
}

\section{RURAL LAND TITLING POLICIES: THE CASE OF THE PROVINCE OF CORRIENTES, ARGENTINA}

\section{GUILLERMO GAPEL REDCOZUB}

Facultad de Derecho y Ciencias Sociales y Políticas

Universidad Nacional del Nordeste

ARGENTINA 


\begin{tabular}{cr}
\hline GUILLERMO GAPEL REDCOZUB \\
$146<$ \\
$\begin{array}{cr}\text { POLÍTICAS DE REGULARIZACIÓN DOMINIAL DE TIERRAS RURALES... } \\
\text { Págs. } 145 \text { - 160. DOI: http://dx.doi.org/10.30972/rfce.0203259 }\end{array}$ \\
\hline & $\begin{array}{r}\text { Recibido: } 12 / 05 / 2018 \\
\text { Aceptado: } 06 / 09 / 2018\end{array}$
\end{tabular}

\title{
RESUMEN
}

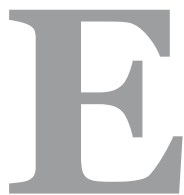

n la Provincia de Corrientes, las políticas que vienen abordando el problema de la informalidad dominial rural en últimos 10 años fueron establecidas mediante la Ley $\mathrm{N}^{0} 5.836$, modificada por Ley $\mathrm{N}^{0} 6.211$ y reglamentada por el Decreto $\mathrm{N}^{0}$ 2.427/08. Este bloque normativo crea un Plan de Regularización Dominial que presenta imprecisiones jurídicas notables, pero más importante aún, se basa en el controversial procedimiento administrativo previsto en la Ley Nacional $\mathrm{N}^{\circ}$ 24.374, el que se ha intentado adaptar al plano provincial con relevantes inconsistencias, y sin que se logre una coordinación eficaz de acciones con municipios y colegios profesionales. Además, responde a un paradigma regularizador basado principalmente en la generación de títulos, el que recibe objeciones por su ineficacia para combatir las razones de fondo que ocasionan la informalidad.

Palabras Clave: regularización dominial, tierras rurales, tenencia de la tierra, derechos de propiedad, Corrientes.

\begin{abstract}
The Province of Corrientes has been developing a land regularization policy for rural areas for the past 10 years. Its main characteristics are: 1) it is based upon a procedure to achieve property titles that raises a strong debate about its legality; 2) It did not achieve the goal of teaming up with local governments and professional associations (notaries, lawyers, among others) to foster the execution of the policy; 3) it focuses almost exclusively in producing land titles for poor farmers (rather than building an effective mechanism to provide them additionally with other key resources, such as technology, access to credit, infrastructure, and health and education services), what is criticized as being ineffective to fight the true causes of the problem.
\end{abstract}

Keywords: land regularization, rural land policy, tenure security, property rights - province of Corrientes.

\footnotetext{
$\overline{{ }^{1} \text { Recupera y profundiza la temática tratada en la ponencia titulada "La Regularización de Tierras Rurales en la Provincia de }}$ Corrientes", presentada en el IV Congreso Nacional de Derecho Agrario Provincial, realizado en Salta (Argentina) en junio de 2017.
} 


\section{INTRODUCCIÓN}

Como consecuencia de las rígidas exigencias legales previstas en el Código Civil y Comercial para la adquisición de derechos reales, de las complejidades y los altos costos de los procesos de usucapión y sucesorios, de arraigadas prácticas inmobiliarias que se resisten a adecuarse a la normativa vigente, de la situación de grave vulnerabilidad socioeconómica de amplios sectores de la población rural, y de la ausencia o falencia de las políticas nacionales y locales en la materia, entre otros factores, la informalidad dominial de las tierras rurales parece incrementarse velozmente.

En el 2012 el Senado correntino trató la cuestión en ocasión de instrumentar una serie de modificaciones al Plan de Regularización de Tierras Rurales que se había sancionado unos cuatro años antes. En el debate producido en el recinto se mencionó que el problema agobiante de la falta de vivienda y de la migración desde el sector rural hacia las ciudades se origina en la carencia de seguridad en la tenencia de la tierra por parte de los pobladores rurales. Se hizo referencia a que la regularización prevista sufría dificultades porque los colonos no estaban en condiciones de cubrir los gastos necesarios (como los de confección de mensuras), y que se tornaba imperioso que el Estado se haga cargo de estos costos. También se explicó que el plazo estipulado en la norma anterior había fenecido, por lo que debían proceder a prorrogarlo². Producto de esta última reforma legislativa, el Plan de Regularización Dominial local adquirió su fisonomía actual.

\section{EL PROBLEMA DE LA TENENCIA DE LA TIERRA EN CORRIENTES ${ }^{3}$}

La extensión precisa del fenómeno resulta difícil de cuantificar, en parte debido a la misma naturaleza de la tarea (asentamientos geográficamente dispersos, de ardua localización y acceso), y en parte porque el Estado no ha dedicado suficiente atención política y recursos para completar la recolección de la información necesaria.

Uno de los escasos estudios disponibles y relativamente recientes, el Informe final del "Relevamiento y sistematización de los problemas de tierra de los agricultores familiares" (Bidaseca, 2014), señala que se han detectado al año 2011 más de 850 situaciones problemáticas

\footnotetext{
${ }^{2}$ Extracto de la Versión Taquigráfica de la 26 Sesión Ordinaria del Honorable Senado de la Provincia de Corrientes, celebrada el 27/09/2012.

${ }^{3}$ Resulta necesario tener presente que en la temática la voz "tenencia" no se emplea con el sentido técnico-jurídico del art. 1910 del Código Civil y Comercial, sino que refiere a la relación entre personas, en cuanto individuos o grupos, con la tierra. En razón de que este es el significado utilizado comúnmente en la literatura que trabaja la problemática, hemos decidido aquí mantenerlo, pese a que no refleja con adecuado rigor técnico los conceptos jurídicos involucrados en la discusión.
} 
vinculadas a la tenencia de la tierra en todo el país, las que afectan a casi 64.000 familias de agricultores y abarcan 9,3 millones de hectáreas. El 88\% de estos conflictos involucra a agricultores familiares que son poseedores y que carecen de título de propiedad. También revela que el 74\% de éstos agricultores familiares cuenta con una posesión suficientemente antigua como para iniciar juicio de usucapión. Respecto de las causas por las cuales estos agricultores no logran acceder al título de propiedad, en función de los relevamientos efectuados en las provincias de Salta, Catamarca, Misiones, Corrientes, San Juan y Santa Cruz, se destacan como principales factores generales: los costos de juicio de usucapión, los costos de la mensura, la falta de asesoramiento, el desconocimiento de los derechos y obligaciones -del poseedor, presumiblemente-, y la existencia de problemas en el acceso a la justicia.

De acuerdo al citado Informe, en la Provincia de Corrientes, los obstáculos para acceder al título de propiedad que enfrentan los agricultores son análogos a los del resto del país. Un 40\% alega no poder cubrir los costos de confección de la documentación necesaria para iniciar el juicio de usucapión, o del proceso mismo ${ }^{4}$; un 49\% manifiesta que desconocen cuáles son sus derechos y que les falta asesoramiento adecuado. Entre otras dificultades, el estudio recaba que los agricultores están geográficamente alejados y les cuesta trasladarse a los centros urbanos para realizar los trámites necesarios, y que tienen temor de que sus reclamos generen represalias por parte de los políticos locales.

Si bien, como explica Slutzky, las problemáticas vinculadas a la tenencia de la tierra no se reducen exclusivamente a la falta de títulos de propiedad, esta carencia origina situaciones básicas de inestabilidad por potenciales desalojos, además de acotar la posibilidad de acceder a créditos para incorporar capital, dificultando enormemente la consolidación productiva de los pequeños establecimientos familiares (Slutzky, 2008).

Específicamente en relación a la inseguridad generada por la ausencia de títulos, el relevamiento citado (Bidaseca, 2014) indica que el $58 \%$ de las familias correntinas que han participado del estudio han sufrido amenazas o presiones de desalojo por problemas de tierras, y que solo el 6\% ha contado con la representación de un abogado. Extrañamente, ninguna familia ha reconocido la existencia de alguna orden de desalojo, lo que podría interpretarse, en el contexto descripto, como evidencia de que las disputas territoriales se resuelven esencialmente en forma extrajudicial o por mano propia, y no ante los tribunales y con las debidas garantías procesales.

Esta situación de inestabilidad en la tenencia de la tierra y de escasez de recursos para afrontar los gastos de un proceso judicial de usucapión ha sido observada por los legisladores locales en oportunidad de actualizar el Plan de Regularización Dominial. En su fundamentación, sin embargo, no formulan referencias a las amenazas y presiones que sufren los poseedores para abandonar los inmuebles. Cabe destacar, también, que los legisladores parecen

\footnotetext{
${ }^{4}$ A modo de referencia vale mencionar que los costos de un proceso de usucapión (gastos de elaboración de mensuras, honorarios judiciales de abogados y de eventuales peritos, tasas administrativas y judiciales, entre otros conceptos) pueden oscilar en torno al $30 \%$ del valor de mercado del inmueble.
} 
entender la cuestión como mero apéndice de un conflicto de orden superior, el de las migraciones rurales hacia ciudades que no están en condiciones de absorberlas, antes que como un problema en sí mismo.

\section{LOS BENEFICIOS DE LA REGULARIZACIÓN}

La literatura especializada en la materia remarca que los beneficios de la regularización dominial se manifiestan, en general, por medio de dos canales: incrementos de inversión en la explotación agropecuaria y/o en la vivienda de las familias que reciben el título de propiedad, y mejores condiciones de acceso al crédito por parte de éstas familias, las que ahora podrían ofrecer garantías reales a las instituciones crediticias privadas y públicas. A continuación brindaremos un panorama de las ventajas que reportan este tipo de políticas en función de las conclusiones de un conjunto de estudios efectuados principalmente sobre Latinoamérica y Argentina.

Lawry, Samii, Hall y otros (2014) han hallado que en Latinoamérica la entrega de títulos a pequeños productores puede generar incrementos significativos en la inversión en las explotaciones, en la productividad agrícola y en los ingresos de los productores. Agregan, sin embargo, que puede tomar un tiempo hasta que las mejoras en la productividad se vuelvan ostensibles, y que estos efectos dependerán en cada caso concreto también de otros elementos, como el acceso al crédito, la oferta de insumos y las características de los mercados donde se comercialicen los bienes producidos.

Deininger y Feder (2009) encontraron amplia evidencia de la existencia de efectos positivos derivados de la formalización de la ocupación, los que se manifiestan en mayores niveles de inversión, menos necesidad de actividades tendientes a proteger la tenencia (liberando mano de obra) y, en ciertos casos, una mejora en la situación de las mujeres. Al igual que los anteriores autores, advierten que la efectiva concreción de estas ventajas se encuentra supeditada a las condiciones socioeconómicas generales y a la naturaleza de las políticas de intervención. Las pruebas de que la entrega de títulos haya mejorado el acceso al crédito son, aseguran, insuficientes.

Payne, Durand-Lasserve y Rakodi (2009), mas escépticos, sostienen que los procesos de titulación contribuyen a incrementar la seguridad en la tenencia de la tierra, pero que ello no repercute necesariamente en mejoras en los niveles de inversión ni en el acceso al crédito. La clave reside, subrayan, en detectar en cada caso particular si el otorgamiento del título modifica verdaderamente la percepción del destinatario de que no será desalojado. Cuando este grado de seguridad es elevado, aunque no cuente con derechos formalizados, los títulos no serían importantes para alterar sus decisiones de inversión en mejoras productivas o habitacionales. 
Para Schweigert (2006), a partir de un estudio realizado en Guatemala, el título de propiedad resulta clave porque incrementa la seguridad en la tenencia de la tierra, incentivando al productor a que invierta en su explotación y eleve así sus niveles de producción. En línea con estos argumentos López y Valdéz (2000) resaltan que las políticas de regularización dominial consistentes en la entrega de títulos pueden ser efectivas en Latinoamérica: les atribuyen en Honduras una mejora en el ingreso promedio de los productores del orden de $5 \%$ per capita, aunque no se han visto especialmente beneficiados los agricultores de menores recursos. Los resultados son similares para los estudios analizados por estos autores respecto del Paraguay.

Específicamente respecto de Argentina, son conocidos los trabajos de Galiani y Schargrodsky (2004 y 2010) sobre asentamientos informales en la periferia de Buenos Aires. Detectaron que las familias que contaban con títulos incrementaron sustancialmente su inversión en vivienda, redujeron su tamaño o cantidad de miembros, aumentaron la educación de sus niños, mejoraron algunos indicadores de salud (peso por altura de los niños) y redujeron las tasas de embarazo adolescente. Concluyen en que el otorgamiento de títulos puede ser una herramienta importante para la reducción de la pobreza a través del desarrollo de la inversión en capital físico y humano.

\section{EL PLAN DE REGULARIZACIÓN DOMINIAL CORRENTINO}

La problemática de las irregularidades dominiales rurales es abordada por localmente mediante la Ley $\mathrm{N}^{0} 5.836$, sancionada el 11/06/2008 y modificada por Ley $\mathrm{N}^{0} 6.211$ del 05/o6/2013. La norma fue reglamentada por el Decreto $\mathrm{N}^{0} 2.427$ (22/10/2008). ${ }^{5}$

En su versión actual esta ley declara la emergencia habitacional con carácter permanente de los asentamientos poblacionales pendientes de regularización en las áreas suburbanas y rurales del territorio provincial ${ }^{6}$. Crea el Plan de Regularización Dominial (PRD), cuyos objetivos centrales son: promover el acceso a los títulos de dominio, en especial para ciertas áreas consideradas prioritarias ${ }^{7}$, formular e implementar planes para incorporar y asignar tierras a las explotaciones agropecuarias de menor escala, y articular con los Colegios Profesionales y los Municipios la ejecución del PRD.

\footnotetext{
${ }^{5}$ No se incluye en el estudio la Ley N ${ }^{\circ} 6124$ de Desarrollo Rural porque entre sus objetivos específicos o centrales no se encuentra el de promover la regularización dominial, aunque el Instituto de Desarrollo Rural que ella crea pueda eventualmente contribuir a dicho propósito.

${ }^{6}$ Aunque la norma no lo dice expresamente, se deduce que está limitada a asentamientos situados sobre terrenos que pertenecen a particulares y no al domino estatal.

${ }^{7}$ En el Decreto Reglamentario se dispone que revisten carácter de áreas prioritarias aquellas cuyos pobladores se encuentren bajo formas jurídicas precarias de ocupación (sin título de propiedad) o estén asentados en zonas bajas, inundables y/o sometidas a condiciones ambientales desfavorables (art. 1). Los parámetros elegidos aquí son inidóneos, o bien por redundantes o bien por insensatos (¿para qué regularizar a familias en terrenos inundables o contaminados? ¿no deberían ser relocalizadas en vez de arraigadas en esos inmuebles en los que se encuentran en situaciones desfavorables?).
} 
Establece quiénes serán los beneficiarios del PRD: las personas físicas poseedoras de inmuebles o de una fracción de inmueble y su núcleo familiar; el cónyuge supérstite y los herederos del ocupante que hayan continuado la ocupación del inmueble; ciertos convivientes (que cuenten con una antigüedad determinada, hayan recibido trato familiar del ocupante y continúen en la ocupación del inmueble luego de su fallecimiento); y los que mediante acto legítimo fuesen continuadores de "dicha” posesión (refiriéndose, aparentemente, a cualquiera de las anteriores supuestos).

No pueden acceder al régimen de la Ley los poseedores de "otros inmuebles con capacidad para satisfacer sus necesidades de vivienda”, ni pueden regularizarse inmuebles de superficie superior a las 200 has.

El procedimiento se destina específicamente para aquellos beneficiarios que acrediten la posesión ${ }^{8}$ pública, pacífica y continua de un inmueble en el que funciona una unidad productiva familiar o que tiene como destino principal el de casa habitación única y permanente, que revista una antigüedad de 3 años y que se haya iniciado antes del 2005, y que además cumpla con las características previstas en la reglamentación catastral y municipal.

Instaura la gratuidad para todos los trámites que los beneficiarios deban realizar y que sean de jurisdicción provincial, decretando que "en ningún caso constituirán impedimentos, la existencia de deudas tributarias, impositivas o de tasas, sean estas administrativas o judiciales, que recaigan sobre el inmueble".

Como nota sobresaliente se generan dos procedimientos regularizadores, uno para asentamientos de más de una familia y otro para asentamientos familiares. Lo veremos en detalle a continuación.

\section{EL MECANISMO REGULARIZADOR}

Cuando el asentamiento esté constituido por más de una familia, la autoridad de aplicación comenzará por evaluar la factibilidad técnica, jurídica y económica de la regularización. En caso de necesidad se podrá solicitar la cesión, compra y/o expropiación de predios colindantes para su asignación y distribución entre las familias del asentamiento. Luego de declarada la factibilidad, se da curso a un proyecto de regularización que relevará los datos personales de los beneficiarios, las características del inmueble (ubicación, medidas, linderos, datos dominiales y catastrales), y las pruebas de la posesión invocada. Una vez concluida esta

\footnotetext{
${ }^{8}$ De acuerdo al art. 9 del Dec. Reg., los interesados deberán acreditar su posesión presentando boleto de compraventa (con firma certificada por escribano o Juez de Paz), escritura de cesión de derechos posesorios o hereditarios a favor del beneficiario, constancias de pago de impuestos y servicios, constancias de haber realizado mejoras (en caso de existir), constancia policial de residencia del beneficiario y su grupo familiar, plano de mensura (si lo tuviere). En caso de que el ocupante "primigenio" hubiese fallecido, los beneficiarios que deseen acogerse al régimen deberán además probar el vínculo con el causante y el cumplimiento de los restantes recaudos exigidos (mediante declaratoria de herederos y/o proceso de información sumaria).
} 
etapa el proyecto quedará limitado a los beneficiarios censados. Desde este punto en adelante, el trámite es prácticamente análogo al de regularización de "asentamientos de una familia". ${ }^{9}$

El paso a paso del procedimiento: los beneficiarios que deseen acceder al régimen deben presentar una solicitud de acogimiento ante la autoridad de aplicación, con sus datos personales, las características del inmueble, los títulos y demás documentación que obrase en su poder y que pudiese ser útil a los efectos de acreditar su posesión y antigüedad; junto con una declaración jurada en la que conste su carácter de poseedor y las condiciones de adquisición de la posesión.

La autoridad de aplicación practicará las verificaciones respectivas y llevará a cabo un relevamiento social..$^{10}$ En caso de que la solicitud fuere procedente, la autoridad de aplicación recolectará los antecedentes dominiales y catastrales del inmueble. De no contarse con estos últimos se dispondrá la confección de los planos pertinentes y su inscripción, con cargo al Estado si el beneficiario careciese de recursos.

La autoridad de aplicación citará al titular registral del dominio de manera fehaciente en el último domicilio conocido y mediante edictos en el Boletín Oficial y en un diario local, emplazando también a cualquier persona que se considere con derechos sobre el inmueble para que deduzca oposición en el término de 30 días.

Frente a este emplazamiento el esquema contempla la ocurrencia de diferentes escenarios:

1) Si no existe oposición se remiten las actuaciones administrativas a la Escribanía Mayor de Gobierno, donde se labrará una escritura-acta con la relación de lo actuado. Será suscripta por el interesado y la autoridad de aplicación, procediéndose luego a su inscripción registral bajo estricta indicación de que obedece a las disposiciones de esta ley.

2) Si se dedujese oposición, sea por el titular registral o por un tercero, se interrumpirá el procedimiento, salvo que el planteo se sustente en la existencia de un saldo de precio impago o en impugnaciones al mismo trámite administrativo, en cuyo caso éste continuará hasta su finalización y sin perjuicio de las acciones legales que pudiere interponer quien se vea afectado.

3) Si el titular del dominio comparece y presta su consentimiento para la transmisión a favor del peticionante, la escrituración se realizará conforme a las normas del derecho común.

La inscripción registral se convertirá de pleno derecho en dominio perfecto transcurrido el plazo de diez años contados desde su registración.

\footnotetext{
${ }_{9}^{9}$ De hecho, no resulta del todo claro si en el supuesto de asentamientos plurifamiliares el objetivo del PRD fue constituir una suerte de estado de condominio entre todas las familias beneficiarias. Pese a que emplea la expresión "asentamientos de área rural compuestos por una pluralidad de familias en forma comunitaria” (art. 8.1., el destacado es propio), el análisis del procedimiento parece indicar que el resultado del trámite será en todos los casos un título de dominio "unifamiliar". En este sentido, sería razonable concluir que el trámite para asentamientos plurifamiliares puede ser considerado como la antesala o etapa previa de las presentaciones individuales. Su finalidad habría sido esencialmente la de evitar potenciales conflictos entre vecinos y miembros de la misma comunidad, brindando un mecanismo para adquirir con antelación las tierras necesarias de manera tal que ninguno se vea perjudicado por la implementación del PRD.

${ }^{10}$ Este relevamiento se integraría con informes elaborados por agrimensores y asistentes sociales sobre la situación socioeconómica de los posibles beneficiarios (Dec. Reg. art. 11).
} 


\section{LOS FUNDAMENTOS DE LA ELECCIÓN DE ESTE MECANISMO REGULARIZADOR}

La Ley $\mathrm{N}^{0}$ 6.211 que modifica al PRD original reconoce que el programa previsto en un primer momento padece un serio defecto: no establece con claridad cuál es el procedimiento a seguir para obtener la titulación de dominio a favor de los beneficiarios declarados.

Con la finalidad de superar este obstáculo se recurre a la metodología diseñada por la Ley $\mathrm{N}^{0}$ 24.374 de Regularización Dominial ${ }^{11}$, la que ciertamente traza un sendero poco ortodoxo hacia la obtención del título de propiedad (Adrogué, 1995). El justificativo de la adopción de este mecanismo radica, según se expresa en el mismo proyecto de ley, en el ostensible éxito que ha tenido su aplicación en la Provincia de Buenos Aires (asegura que allí se han entregado más de 150.000 escrituras merced a este procedimiento). Entre sus principales ventajas se destacan la celeridad del trámite (que se podría completar en seis meses) y sus bajos costos.

Sin embargo, al adoptar localmente el procedimiento regularizatorio creado a nivel nacional se han introducido algunas modificaciones:

CUADRO 1

\begin{tabular}{|c|c|c|}
\hline & Ley Nacional № 24.374 & Ley Provincial № 5.836 \\
\hline $\begin{array}{c}\text { Inmuebles } \\
\text { Comprendidos }\end{array}$ & $\begin{array}{l}\text { Urbanos y edificados, con destino } \\
\text { principal de casa habitación única; o } \\
\text { rurales donde residan y produzcan } \\
\text { agricultores familiares }\end{array}$ & $\begin{array}{c}\text { Inmuebles suburbanos y rurales, con destino } \\
\text { de casa habitación única o que constituyan } \\
\text { una unidad productiva familiar }\end{array}$ \\
\hline Exclusiones & No impone exclusiones por superficie & Inmuebles de más de 200 has. \\
\hline Causa de la Ocupación & Debe ser lícita & No se exige licitud en forma expresa \\
\hline $\begin{array}{l}\text { Costo del Procedimiento } \\
\text { para el beneficiario }\end{array}$ & $\begin{array}{c}1 \% \text { del Valor Fiscal } \\
\text { del inmueble }\end{array}$ & En principio, sin costo \\
\hline
\end{tabular}

Fuente: elaboración propia.

Es decir, Corrientes ha optado por implementar un sistema regularizador que fue pensado específicamente por el legislador nacional para sanear la situación de viviendas urbanas, cambiando su objeto y destinándolo en forma exclusiva a inmuebles suburbanos y rurales que pueden constituir unidades productivas.

Además, resulta indispensable destacar que el esquema previsto por la Provincia de Buenos Aires, tomado como modelo de eficacia por el legislador local, no sólo se circunscribe a predios urbanos, sino que también instaura un conjunto de "Registros Notariales de Regularización Dominial”. Estos Registros desempeñan un papel clave en el funcionamiento

${ }^{11}$ Esta norma es modificada por las Leyes № 25.797, № 26.493 y № 27.118. Fue reglamentada por Decreto № $1885 / 94$. 
del sistema de regularización, asumiendo la responsabilidad de ejecutar el procedimiento previsto en la Ley $\mathrm{N}^{\circ}$ 24.374, bajo la supervisión del Colegio de Escribanos y de la autoridad de aplicación. ${ }^{12}$

Por lo tanto, el proyecto correntino fue conformado siguiendo los lineamientos de un modelo base que tiene por finalidad la regularización de inmuebles con destinos y ubicaciones diferentes. Estas variables son trascendentes y se deben tener en consideración a la hora de diagramar la regularización dominial: las operaciones de mensura y deslinde, así como las pruebas disponibles para acreditar la existencia y antigüedad de la posesión difieren en el ámbito urbano y en el rural. Lo mismo sucede con las posibilidades reales de los beneficiarios de acceder a los programas de saneamiento de títulos y cumplir con los trámites exigidos: por sus menores ingresos y niveles de instrucción formal, y por su aislamiento geográfico, entre otros factores, la situación de vulnerabilidad de los beneficiarios rurales es en general más acuciante que la de los poseedores urbanos, lo que no puede ser soslayado a la hora de planificar este tipo de políticas.

Las capacidades burocráticas indispensables para llevar adelante la regularización dominial tampoco serán idénticas en el ámbito urbano y en el rural. La Administración deberá formar y seleccionar, para cada caso, recursos humanos con los perfiles adecuados y dotarlos además del equipamiento requerido para cumplir satisfactoriamente su cometido. En virtud de ello, huelga decir que los costos de combatir la informalidad urbana y rural serán también notablemente disímiles, tanto para los particulares como para el Estado, lo que debería reflejarse en la asignación de presupuestos adecuados para cada programa.

El PRD tampoco logró dar forma acabada a la intervención coordinada de actores gubernamentales y no gubernamentales que cumplen tareas centrales en la eficaz implementación de la política de saneamiento bonaerense. En efecto, los responsables de esta experiencia destacan que: ... el sistema se sustenta en tres pilares: El primero es el escribano, quien con el apoyo institucional del Colegio asume un rol en el proceso que va más allá de su función fedataria, ya que realiza una actividad administrativa judicial al tramitar un expediente, en el cual requiere y recibe la prueba, y meritúa si se encuentran cumplidos los requisitos previstos para otorgar el acta. Su actuación garantiza la legalidad y certeza que deben tener el procedimiento y la protección de derechos de terceros.

En segundo lugar la Subsecretaría Social de Tierras, Urbanismo y Vivienda que, como autoridad de aplicación, tiene un rol fundamental, el de llevar adelante el proceso, a través de la implementación, control, vinculación con las personas que requieran acceder al sistema, los visados y otorgamiento por el titular del organismo del acta de regularización dominial y, oportunamente, su consolidación.

\footnotetext{
${ }^{12}$ La Ley Nacional № 24.374 es reglamentada en la Pcia. de Buenos Aires por el Decreto № 2815/96, modificado por los Decretos № 3237/02 y № 876/05. Estos antecedentes bonaerenses eran conocidos, al menos en parte, por el legislador correntino. Se mencionan expresamente en los fundamentos del Proyecto de la Ley № 6.211, aunque luego no tienen impacto real en el diseño final del PRD.

El rol de los Registros Notariales de Regularización Dominial es explicado en detalle en Muñoz (2008).
} 
Finalmente, los municipios se constituyen en el tercer pilar en que se asienta el proceso, cuando promueven el conocimiento de la ley, generan el interés de los futuros beneficiarios sumándolos al sistema y colaboran con los regularizadores en la obtención de la prueba y la concreción del proceso.

La coordinación entre los tres actores permite una coconstrucción superadora, ya que se complementan las diferentes fortalezas, competencias y capacidades de cada estamento interviniente (Colegio de Escribanos y Subsecretaría de Tierras de la Pcia. de Buenos Aires, s/f, p. 6).

En el caso bajo estudio, si bien es cierto que el PRD tiene dentro de sus objetivos el de articular su implementación con los Colegios Profesionales y las jurisdicciones municipales mediante la asistencia técnica y la coordinación de acciones, no se aprecia que en la ejecución del mismo se haya alcanzado este nivel de cohesión entre diferentes actores que en la experiencia bonaerense se considera determinante.

\section{REFLEXIONES SOBRE EL PROCEDIMIENTO CORRENTINO DE REGULARIZACIÓN DE TIERRAS RURALES}

Finalmente quisiéramos formular algunas consideraciones de índole jurídica, política y operativa sobre la cuestión.

En materia jurídica, al seguir prácticamente al pie de la letra al procedimiento previsto en la Ley $\mathrm{N}^{\circ}$ 24.374, el PRD correntino es pasible de los cuestionamientos que se le han hecho a la citada normativa ${ }^{13}$. En este sentido, Mariani de Vidal (2010) se pregunta por la legalidad de un trámite administrativo que concluye privando de su dominio al propietario originario sin que medie intervención judicial, en franca contradicción con el art. 17 de la Constitución Nacional. Borda (1994) y Sagarna (1996) se inclinan directamente por la inconstitucionalidad de la norma. Este último autor inclusive enumera las "múltiples inconstitucionalidades" que se observan en la Ley $\mathrm{N}^{\circ}$ 24.374:

a) Es inconstitucional por violar el derecho de propiedad (art. 17, Constitución Nacional), ya que administrativamente se está disponiendo la inscripción de una "escritura" sin la intervención debida del titular del dominio pues la citación y el emplazamiento estipulado en el art. $6^{\circ}$, inc. d), no son de lo más eficientes;

b) es inconstitucional por darle a la administración facultades propias del Poder Judicial;

\footnotetext{
${ }^{13}$ La ley correntina sería inclusive objetable por violar el principio de numerus clausus o serie cerrada consagrado en el artículo 2505 del Código Civil (hoy derogado) y actualmente en el artículo 1884 del Código Civil y Comercial argentino. De acuerdo al mismo, la adquisición de derechos reales únicamente puede ser regulada mediante ley nacional, y las modificaciones que pretendan introducir al respecto los Estados provinciales son nulas.
} 
c) es inconstitucional por desconocerse el principio de igualdad ante la ley de las personas en cuanto hace a los inmuebles no urbanos que quedan fuera del amparo de la norma (art. 16, Constitución Nacional);

d) es inconstitucional por no respetar el principio de igualdad de las personas ante los impuestos y las cargas públicas, estos nuevos beneficiarios no tendrán la obligación que tiene cualquier vendedor de tener el bien al momento de la venta libre de deudas tributarias (art. 16, Constitución Nacional);

e) es inconstitucional por no observar el principio de igualdad ante la imposición de una fecha tope por demás arbitraria. (Sagarna, 1996:10).

Frente a tantas inconsistencias, concluye el autor, lo más conveniente sería que la Ley sea derogada para evitar una esperable acumulación de litigios (Sagarna, 1996).

Peralta Mariscal (1995), por su parte, refiere que esta norma debió haber sido vetada en su totalidad por el Poder Ejecutivo, mientras De Rosa y Abadie (2012) advierten sobre el peligro que representa el hecho de que las provincias avancen sobre formas cuya regulación estaría reservada al Congreso Nacional (art. 74 inc. 12 de la C.N.).

Pese a las críticas manifestadas por los doctrinarios, no hemos tomado conocimiento de que los tribunales a la fecha hayan acogido favorablemente planteos de inconstitucionalidad de la norma. Por el contrario, los escasos fallos que han trascendido lo consideran un sistema válido aunque de excepción ${ }^{14}$; que resulta constitucional pues protege el derecho a la vivienda garantizada por el art.14 de la CN y que no afecta a la inviolabilidad de la propiedad garantizada por el art. $17 \mathrm{CN}$, porque lo que obtiene el beneficiario es un título idóneo para la usucapión breve, quedando a salvo los derechos de terceros ${ }^{15}$.

Un estudio más profundo acerca de la constitucionalidad del régimen creado por esta ley nacional, así como de su compatibilidad con el Código Civil y Comercial es una tarea aún pendiente para los especialistas y que excede a la finalidad de este artículo. No obstante, coincidimos con los autores que se lamentan que el Congreso Nacional no haya aprovechado la oportunidad para sancionar una regulación saneadora que sea sencilla y clara ${ }^{16}$, agregando que la decisión local de reproducir un mecanismo de regularización tan controversial, alterando además los pilares de la versión en implementación a la que toma por modelo, no haya sido probablemente una estrategia aconsejable para abordar la tarea.

Quizás por ello, próximo a cumplir diez años de vigencia, el PRD no puede demostrar que ha conseguido logros significativos en relación a la dimensiones de una problemática generalizada y de tendencia creciente ${ }^{17}$. Sin poner en tela de juicio el denodado y notable esfuerzo de

\footnotetext{
${ }^{14}$ Cámara de Apelaciones en lo Civil y Comercial de Morón, 14/05/2009, Crédito Edificador y Pavimentador S.A. c/ Arguello Roberto y Otros s/ Reivindicación de Inmueble.

${ }^{15}$ Cámara de Apelación en lo Civil y Comercial de Mercedes, Sala III, 04/08/2009, Félix Antonio Vicente c/Sucesión de Benito Curkovic s/nulidad de escritura pública.

${ }^{16}$ Mariani de Vidal, obra citada, p. 387.

${ }^{17}$ En los últimos tres años unas cuatrocientas familias correntinas habrían recibido o estarían tramitando los "títulos" de la Ley № 5836, de acuerdo a fuentes periodísticas: http://diariolarepublica.com.ar/notix/
} 
los funcionarios que trabajan en el área, lo cierto es que el instrumento elegido parece no ser el adecuado para abordar el fenómeno.

Por último, corresponde tener presente que una corriente de especialistas en asentamientos informales cuestionan fuertemente las políticas de regularización que se centran exclusiva o primordialmente en el aspecto de la titulación, remarcando la necesidad de complementar estas medidas con la ejecución de programas socioeconómicos para promover la integración socioespacial de las áreas y comunidades informales. Explican que la titulación no puede cumplir con sus finalidades si se implementa sin tener en cuenta a las redes de seguridad social y la provisión de bienes públicos en cantidad y calidad suficiente - salud, educación, transporte(Fernandes, 2011). Destacan, además, que en el ámbito rural, "la problemática de la tenencia de la tierra no se puede enfocar en forma aislada sino articulada con un programa de consolidación productiva de los pequeños productores que son los más afectados por la misma" (Slutzky, 2008: p.42).

En concordancia con estas ideas, los estudios de la Organización de las Naciones Unidas para la Alimentación y la Agricultura concluyen en que si bien una mayor seguridad en la tenencia de la tierra representa una parte importante del desarrollo rural, ello no es de por sí solo suficiente, siendo también indispensable el acceso al financiamiento, capacitación, mercados abiertos y eficaces y las mejoras en tecnología e infraestructura rural para que los beneficios de este tipo políticas puedan finalmente concretarse. El abordaje integral propuesto en estos estudios también incluye la consideración de cuestiones ambientales, con la finalidad de evitar la degradación de los recursos naturales; y la necesidad de promover la equidad de género, puesto que un número importante de familias rurales tienen por jefe de hogar a una mujer y esta característica puede dificultar su participación en los programas de regularización (por padecer frecuentes discriminaciones o abusos, contar con menores recursos económicos o menor nivel de instrucción, poseer mayores responsabilidades familiares que le restan disponibilidad horaria para efectuar trámites, entre otros factores) (FAO, 2003).

Este enfoque multidimensional del fenómeno no parece haber sido tenido suficientemente en cuenta en oportunidad de diseñar y ejecutar la normativa bajo estudio.

En síntesis, el Plan de Regularización Dominial de Tierras Rurales correntino se apoya en un procedimiento jurídicamente cuestionado, "adaptado" localmente con notables inconsistencias, que no ha logrado convocar y coordinar eficazmente las acciones con municipios y colegios profesionales, y que responde, finalmente, a un paradigma regularizador que recibe objeciones por su incapacidad para combatir las razones de fondo que generan la informalidad.

Todo ello indica que es tiempo de repensar profundamente las políticas locales de regularización de tierras rurales. 


\section{REFERENCIAS BIBLIOGRÁFICAS}

Adrogué, Manuel (1995): "La atribución de la propiedad de la vivienda económica en la ley 24.374”. La Ley 1995-B, 934. Cita Online: AR/DOC/11787/2001.

Bidaseca, Karina (2014): "Procesamiento y actualización de datos del Estudio Relevamiento y sistematización de los problemas de tierra de los agricultores familiares de la República Argentina" en seis provincias afectadas por el fenómeno de land grabbing”. Documentos de Investigación Social, Universidad Nacional de San Martín - IDAES- № 25.

Disponible en www.unsam.edu.ar/institutos/idaes/docs/DocIS_25_Bidaseca.pdf (Consultado el 11/05/2018).

Borda, Guillermo (1994): "Un grave avance sobre la propiedad privada". La Ley, supl. Diario del 02.05.94.

De Rosa, Diego y Abadie, Diego (2012): "Contornos del régimen de regularización dominial de la ley 24.374 y sus modificatorias”. Anales $\mathrm{N}^{0}$ 42, Facultad de Cs. Jurídicas y Sociales, U.N.L.P., 2012.

Deininger, Klaus y Feder, Gershon (2009): "Land Registration, Governance, and Development: Evidence and Implications for Policy”. The World Bank Research Observer, Vol. 24, No. 2 (August 2009), pp. 233-266. Oxford University Press.

Colegio de Escribanos de la Pcia. de Buenos Aires y Subsecretaría Social de Tierras, Urbanismo y Vivienda de la Pcia. de Buenos Aires (sin fecha). "Regularización y consolidación dominial en la Provincia de Buenos Aires". Disponible en: http://www. colescba.org.ar/static/servicios/comunidad/regularizacion/archivos/formularios/2016/ Regularizacion-y-Consolidacion-dominial-en-la-Provincia-de-Buenos-Aires.pdf (Consultado el 10/05/2018).

Food and Agriculture Organization of the United Nations - FAO - (2003): "Estudios sobre la tenencia de la tierra” (3). Disponible en: http://www.fao.org/docrep/o05/y4307s/y4307soo. htm (Consultado el 20/08/2018).

Fernandes, Edesio (2011): "Regularización de asentamientos informales en América Latina". Lincoln Institute of Land Policy. 
Galiani, Sebastian y Schargrodsky, Ernesto (2004): "Effects of land titling on child health". Economics \& Human Biology. Volume 2, Issue 3, December 2004, pp. 353-372. https://doi. org/10.1016/j.ehb.2004.10.003

Galiani, Sebastian y Schargrodsky, Ernesto (2010): "Property Rights for the Poor: Effects of Land Titling”. Journal of Public Economics 94 (2010) 700-729.

Lawry, S.; Samii, C.; Hall, R.; Leopold, A.; Hornby, D. y Mtero, F. (2014): "The impact of land property rights interventions on investment and agricultural productivity in developing countries: a systematic review”. Campbell Systematic Reviews 2014:1. https://www.gov.uk/ dfid-research-outputs/the-impact-of-land-property-rights-interventions-on-investmentand-agricultural-productivity-in-developing-countries-a-systematic-review

Mariani de Vidal, Marina (2010): “Derechos Reales”. Zavalía, Bs. As., 2010, Tomo III.

Muñoz, Lorena (2008): "Regularización Dominial: A más de una década de la Ley 24.374. Estado de la consolidación de dominio en la Provincia de Buenos Aires y una posible actualización del régimen”. UNLP 2008-38, 01/01/2008, 409. Cita Online: AR/DOC/614/2008

Payne,Geoffrey; Durand-Lasserve,Alainy Rakodi,Carole(2009): “Thelimitsoflandtitling andhome ownership". Environment and Urbanization, 2009, 21: 443 - DOI: 10.1177/0956247809344364 Disponible en: http://eau.sagepub.com/content/21/2/443 (Consultado: 05/04/2018).

Peralta Mariscal, Leopoldo (1995): “Algunas consideraciones en torno a la llamada "ley de regularización dominial". Jurisprudencia Argentina, Buenos Aires, Nº 5931, 3 de mayo de 1995, pp. 17-22.

Ramón López y Alberto Valdés (2000): "Fighting Rural Poverty in Latin America: New Evidence of the Effects of Education, Demographics, and Access to Land". Economic Development and Cultural Change, Vol. 49, No. 1 (October 2000), pp. 197-211. The University of Chicago Press.

Sagarna, Fernando (1996): "La ley 24.374 de regularización dominial: una fuente de litigios". La Ley 1996-D, 975. Cita Online: AR/DOC/18337/2001

Schweigert, Thomas (2006): "Land Title, Tenure Security, Investment and Farm Output: Evidence from Guatemala”. The Journal of Developing Areas, Vol. 40, No. 1 (Autumn, 2006), pp. 115-126. College of Business, Tennessee State University. 
Slutzky, Daniel (2008): “Situaciones problemáticas de tenencia de la tierra en Argentina”. Ministerio de Economía y Producción - Secretaría de Agricultura, Ganadería, Pesca y Alimentos - Dirección de Desarrollo Agropecuario - PROINDER - Serie Estudios e Investigaciones No 14. Disponible en redaf.org.ar/wp-content/uploads/2008/o8/problematicas-de-tenencia-dela-tierra.pdf (Consultado el 12/04/2018).

\section{COMO CITAR ESTE ARTÍCULO:}

GAPEL REDCOZUB, Guillermo. Políticas de regularización dominial de tierras rurales: el plan de la provincia de Corrientes, Argentina. Revista de la Facultad de Ciencias Económicas - UNNE. Número 20, otoño 2018, ISSN 1668 - 6365. Págs. 145 - 16o. DOI: http://dx.doi. org/10.30972/rfce.0203259

\section{CURRICULUM VITAE}

\section{Guillermo Gapel Redcozub}

Abogado, Facultad de Derecho, Universidad Nacional del Nordeste (UNNE). Licenciado en Economía, Facultad de Ciencias Económicas (UNNE). Especialista en Docencia Universitaria, Facultad de Humanidades (UNNE). Master of Laws (Harvard Law School, E.E.U.U.). Profesor Titular Regular de Derechos Reales, Facultad de Derecho (UNNE).

guillermogapel@gmail.com 